\title{
La integración regional en la política migratoria argentina
}

The Regional Integration of the Migration Policy in Argentina

\section{Integração regional na política de imigração argentina}

\section{Julieta Nicolao* • Argentina}

Recibido el 18 de abril de 2011 - aprobado el 10 de mayo de 2011

\section{Resumen}

Objetivo. El objetivo de este artículo es revelar el lugar que ha ocupado el proceso de integración del Mercado Común del Sur (Mercosur) en la definición y orientación que asumió la política migratoria argentina durante el período 2003-2007. Metodología. El estudio se realizó a través de una perspectiva teórica poco explorada en el campo de las políticas migratorias, especialmente para el caso de los países no industrializados, que hace hincapié en el fortalecimiento de su dimensión internacional. Resultados. A partir del año 2003 y durante los cuatro años de presidencia de Kirchner en Argentina, se producen modificaciones en los marcos normativos y regulatorios nacionales en materia migratoria. Estas medidas dan cuenta de un rotundo cambio de orientación en la política migratoria de este país que asume un enfoque más aperturista, regionalista, y con una fuerte impronta en derechos humanos. Conclusiones. Se demuestra que el Mercosur jugó un papel sustancial en la política migratoria de Argentina durante el período bajo estudio. A través de un análisis de la política migratoria en su dimensión explícita -discurso oficial y legislación pertinente- y de la performance argentina en las instancias institucionales migratorias del Mercosur, se concluye además que dicho proceso de integración ha cobrado singular relevancia sobre la política migratoria como resultado de la decisión política nacional de imprimirle a ésta un carácter regionalista.

Palabras claves: política migratoria, dimensión internacional, integración regional, Argentina, Mercosur.

* Licenciada en Relaciones Internacionales $•$ Doctoranda en Ciencia Política • argentina $•$ CONICET - CEIPIL (Universidad Nacional del Centro de la Provincia de Buenos Aires)・nicolao_j@yahoo.com.ar 


\begin{abstract}
Objectives. This paper aims at revealing the place that the integration process of MERCOSUR (South America Common Market) had in the definition and orientation of Argentina's migration policy during 2003 and 2007. Methodology. This study was carried out by a not much explored theoretical perspective related to migration policies, especially in non-industrialized countries, which emphasizes on the strengthening of its international dimension. Results. Since 2003 and during the four years of Mrs. Kirchner's Presidency in Argentina, some changes in national regulatory frameworks about migratory issues were produced. These measurements account for a radical change in the migration policy of this country, which assumes an open, regionalist and a noticeable print about human rights. Conclusion. This study shows that MERCOSUR played a main role in Argentina's migration policy during the analyzed period. By an analysis of the explicit migration policy, that is, official discourse and relevant legislation, and the Argentinian performance of the institutional migration entities of Mercosur, it can be also concluded that the integration process has taken a particular importance on the migration policy as a result of the national policy decision of printing it a regionalist mark.
\end{abstract}

Keywords: migration policy, international dimension, regional integration, Argentina, MERCOSUR.

\title{
Resumo
}

Objetivos. O objetivo deste artigo é revelar o lugar que tem ocupado o proceso de integração do Mercado Comum do Sul (MERCOSUL) na definição e orientação que assumiu a política migratória argentina durante o período 2003-2007. Metodologia. O estudo realizou se a través duma perspectiva teórica pouca explorada no campo das políticas migratórias, especialmente para o caso dos países não industrializados, que faz ênfase no fortalecimento de sua dimensão internacional. Resultados. A partir do ano 2003 e durante os quatro anos de presidência de Kirchner em Argentina, se produzem modificações nos marcos normativas e regulatórias nacionais em matéria migratória. Estas medidas dão conta dum rotundo cambio de orientação na política migratória deste país que assume um enfoque mais de abertura, regionalista, e com uma forte impressão em direitos humanos. Conclusões. Demonstra se que o MERCOSUL jogou um papel substancial na política migratória de Argentina durante o período baixo estudo. Através dum analise da política migratória em sua dimensão explicita discurso oficial e legislação pertinente - e do desempenho argentino nas instancias institucionais migratórias do MERCOSUL, exclui se além que este processo de integração tem cobrado singular relevância sobre a política migratória como resultado da decisão política nacional de imprimir lhe a esta um caráter regionalista.

Palavras Chave: política migratória, dimensão internacional, integração regional, Argentina, MERCOSUL. 


\section{Introducción}

La definición de políticas migratorias siempre se ha visto moldeada por factores domésticos como por factores de carácter externo . No obstante, en los últimos años, como consecuencia del acelerado proceso de globalización, de la proliferación de bloques de integración regional, de la plena incorporación de la problemática migratoria a la agenda internacional, y con ella, a las agendas de numerosos organismos internacionales -por mencionar sólo algunos aspectos-, estos últimos han adquirido una relevancia particularmente intensa. Esto se pone en evidencia a través de la proliferación de convenciones internacionales (en materia de refugio, derechos humanos) que moldean obligadamente las legislaciones migratorias de los Estados nacionales; de los esquemas de admisión migratoria diferenciados que se establecen en espacios regionales; de la intensificación de las relaciones entre países de origen y destino en la gestión de los flujos, o de la multiplicación de instancias de diálogo y cooperación a nivel regional e internacional, reflejo del reciente proceso de «politización» de la cuestión migratoria a nivel global (López Sala, 2005).

Ahora bien, "La inmigración fue concebida durante décadas como un fenómeno socioeconómico al que no se le atribuyó significación política" (López Sala, 2005, p. 101). Así lo han puesto sobre el tapete distintos especialistas que destacan la falta de atención que han recibido tradicionalmente los factores políticos, y concretamente, el Estado, en los desarrollos teóricos que desde fines del siglo XIX intentan explicar los procesos migratorios internacionales (Zolberg, 1989; Massey, 1999; Hollifield, 2000; Arango, 2000 y otros). Una serie de hechos empíricos, entre los que destacan la consolidación del patrón migratorio en dirección sur-norte, el desarrollo de la faceta más restrictiva de las políticas migratorias en el contexto global, el creciente impacto político de minorías étnicas en algunos Estados de recepción, influyeron para que, a partir de los decenios de 1970 y 1980, el mundo académico comenzara a dedicar mayor atención a las implicaciones políticas de las migraciones internacionales .

Sin duda, el campo de las políticas migratorias ha sido el más explorado desde entonces -y dentro de éste, la dimensión de las políticas de control y regulación-, multiplicándose los modelos interpretativos construidos desde distintas escuelas de pensamiento (Meyers, 2000). Otro grupo de teorías se ha dedicado al desarrollo de diferentes modelos de integración e incorporación de los inmigrantes a las sociedades de destino (destacando los estudios de Hammar, 1992; Faist, 1996; Entzinger, 2000; Heckmann \& Schnapper, 2003); y el resto de los trabajos se ha centrado en el campo de las políticas de nacionalidad (Brubaker 1989, 1990, 1992; Hammar, 1990; Joppke, 1999; Soysal, 2000; entre otros).

La dimensión internacional de las políticas migratorias -y dentro de ella, todo lo que refiere a su interacción con los objetivos e intereses de la política exterior de los Estados de acogida, las implicancias que conlleva para ellos la pertenencia a organi- 
zaciones supranacionales, así como lo que respecta a las obligaciones derivadas de los compromisos internacionales asumidos, entre otros (Mármora, 2002)-, ha estado lejos de constituir la faceta más explorada. A saber, el grueso de estos estudios, enfocados desde distintas teorías de relaciones internacionales, se han dedicado a teorizar sobre la relación entre las inmigración y la política exterior, desarrollando en mayor medida el caso norteamericano en lo que refiere a la influencia y la proyección de la política exterior y de seguridad sobre su política migratoria en general, y de refugio y asilo en particular (Miller \& Papademetriou, 1983; Teitelbaum, 1984; Loescher \& Scanlan, 1986; Mitchell, 1992; Weiner, 1993; y otros). Del mismo modo, se ha atendido a la influencia que ejercen distintas instancias supranacionales y regímenes internacionales en la definición de las políticas migratorias, sobre todo para el caso europeo (Zolberg, 1992; Hollifield, 1992; Miller, 1992; Cornelius, Martin, \& Hollifield, 1994, entre otros) y del régimen internacional de los refugiados (Salomon, 1991; Skran, 1995 y otros). No obstante, esta faceta no ha sido prácticamente abordada para experiencias de países no industrializados, aunque su relevancia empírica haya ido en aumento en muchos de estos países.

En el plano regional, Mármora (2003) ha puesto de manifiesto que desde el decenio de 1990 el tratamiento institucional de las migraciones internacionales en toda América Latina, a través de los espacios de integración regional, el establecimiento de convenios específicos y de procesos consultivos, comienza a mostrar alternativas de políticas donde la corresponsabilidad y el consenso entre países de origen y destino se convierten en un rasgo característico. Esta modalidad se contrapone radicalmente al tradicional unilateralismo que caracterizó el accionar del Estado en este terreno y que en la etapa contemporánea se ha acentuado a través del incremento de los controles y las restricciones al desarrollo de los flujos migratorios en los países industrializados. Así lo entiende Dublanc: "En los países de la región, el avance de apertura al diálogo y la búsqueda de consensos sobre un tema cargado tradicionalmente de recelos y conflictos ha sido, en los últimos años, muy importante" (2009, p. 246).

En la década de 2000, distintos factores ejercieron influencia en la región, y especialmente en el espacio sudamericano, para que el tratamiento político de la cuestión migratoria se convierta en centro de consultas y formación de consensos. Entre los más importantes destacan el renovado clima político que se vivió en la subregión desde los primeros años del nuevo milenio -vinculado al quiebre del consenso neoliberal en varios de estos Estados-; el acuerdo alcanzado sobre el valor estratégico que reviste la integración regional para los países de la región, así como la importancia que asumen los aspectos políticos, sociales y culturales en tales construcciones; y por último, los cambios en los perfiles migratorios. Al respecto, fue particularmente el incremento de la emigración de sudamericanos que se dirigen a países desarrollados con endurecidas políticas migratorias lo que ha unido a los gobiernos de la región para el diseño e implementación de estrategias de acción conjunta, contribuyendo a una mayor concien- 
tización sobre la problemática migratoria regional y a una mayor predisposición de los gobiernos hacia la búsqueda de compromisos en este terreno. El hecho emblemático fue la creación de la Conferencia Sudamericana de Migraciones (CSM) en el año 2000, que formalizó el diálogo subregional en la materia .

En el contexto sudamericano, Argentina destaca por su condición de receptor histórico de flujos migratorios internacionales y como el principal destino migratorio de América del Sur. De acuerdo al Censo Nacional de 2001 (aún no han sido publicados los resultados oficiales del Censo de 2010 y no existen proyecciones oficiales en la materia), los inmigrantes regionales representaban más del 60\% de toda la población extranjera, superando el millón de personas. La inmigración de este origen es de larga data y siempre ha mantenido un volumen constante, desarrollándose de forma sostenida en el tiempo ; no obstante, en los últimos decenios, como consecuencia de la falta de renovación de las antiguas corrientes migratorias de ultramar y de la defunción de una proporción importante de esta población, comenzó a crecer en términos relativos hasta convertirse en la principal fuente de inmigración del país (Cerrutti, 2009).

\section{Población extranjera de origen regional en Argentina, según el Censo de Población, Hogares y Vivienda 2001}

\begin{tabular}{|c|c|c|c|c|c|c|c|c|}
\hline \multirow{2}{*}{$\begin{array}{l}\text { Población } \\
\text { total del país }\end{array}$} & \multirow{2}{*}{$\begin{array}{l}\text { Población ex- } \\
\text { tranjera sobre } \\
\text { población } \\
\text { total }\end{array}$} & \multirow{2}{*}{$\begin{array}{l}\text { Inmigrantes } \\
\text { regionales sobre } \\
\text { población ex- } \\
\text { tranjera }\end{array}$} & \multicolumn{6}{|c|}{ Distribución de la inmigración regional por país de origen } \\
\hline & & & Bolivia & Brasil & Chile & Paraguay & Perú & Uruguay \\
\hline 36.260 .130 & 1.517 .904 & 1.003 .810 & 231.789 & 33.748 & 211.093 & 322.962 & 87.546 & 116.672 \\
\hline $100 \%$ & $4,2 \%$ & $66 \%$ & $23,1 \%$ & $3,4 \%$ & $21 \%$ & 32,2 & 8,8 & 11,6 \\
\hline
\end{tabular}

Fuente: elaboración propia con base en Censo Nacional de Población, Hogares y Vivienda 2001.

Ahora bien, en Argentina, los estudios sobre migraciones internacionales abarcan una literatura verdaderamente amplia y enfoques de diversas disciplinas, pero no se desvinculan de su evolución global y, por ende, el espectro se vuelve mucho más reducido cuando se trata de investigaciones sobre políticas migratorias. Como señala Novick, "Si bien el aparato estatal argentino posee una temprana y extensa experiencia en la formulación de políticas migratorias, mucho más reciente es el estudio de las mismas desde el campo de las ciencias sociales" (Novick, 1997, p. 86). Asimismo, la literatura existente sobre la forma en que se define y ejecuta la misma en este país ha sido poco desarrollada y ha estado confinada a análisis sobre factores económicos y culturales (Albarracín, 2005); ha sido analizada en el marco de la relación entre la estrategia nacional de desarrollo y las políti- 
cas demográficas desde el ámbito normativo del Estado (Novick, 1991, 1997, 2008, entre otras obras de esta autora), en su dimensión discursiva (Oteiza \& Aruj, 1997; Domenech \& Magliano, 2008; entre otros) y también en lo que refiere a su definición desde enfoques político-técnicos (Mármora, 2002), no así en su dimensión internacional.

A pesar de ello, en el plano empírico, cada vez se hace más evidente y visible su trascendencia. En los últimos años, la política migratoria argentina experimentó un vuelco considerable cuyo punto de inflexión fue la sanción de una nueva ley en la materia bajo la presidencia del Dr. Néstor C. Kirchner (Ley núm. 25.871 / 2003). Esta ley dejó sin vigencia la anterior norma sancionada durante el último gobierno de facto , instalando un nuevo paradigma basado, a grandes rasgos, en la promoción y el respeto de los derechos humanos, una perspectiva regionalista y cierto retorno a la tradición de puertas abiertas que caracterizó al país desde los inicios de su constitución como Estado (Nicolao, 2011). En este contexto, algunos atributos que asumió la misma, tales como el objetivo de iniciar un camino tendiente a la corresponsabilidad y la multilateralidad en la gestión de los flujos, la intención de enmarcarla en los esfuerzos integracionistas sudamericanos, o la incorporación de nuevos convenios internacionales tanto multilaterales como bilaterales, constituyen ejemplos elocuentes.

En suma, el presente estudio parte de concebir que las migraciones internacionales y en consecuencia, las políticas migratorias, han dejado de representar una cuestión de estricta incumbencia doméstica para los países de acogida, pues es innegable que las mismas generan efectos más allá de las fronteras nacionales, comúnmente alterando las relaciones exteriores entre los países involucrados en dichas corrientes. De hecho, en la última década del siglo XX, fueron incorporadas definitivamente como un tema prioritario de la agenda internacional -desapareciendo su tratamiento meramente coyuntural-. En este marco, proliferaron los actores sociales que intervienen en el debate migratorio y en la definición de políticas y cursos de acción -con mayor o menor influencia según el caso-, estableciéndose una articulación cada vez mayor entre los espacios nacional, regional e internacional en su tratamiento político (Domenech, 2007). Dentro de estos actores, los procesos de integración regional emergen como instancias fundamentales. De hecho, algunos especialistas han comenzado a hablar de la emergencia de una nueva tendencia hacia la internacionalización o regionalización de las políticas migratorias (López Sala, 2005).

Lejos de constituir una consecuencia del debilitamiento de la soberanía de los Estados y de su capacidad para regular los movimientos migratorios internacionales, tal como lo han propuesto los estudiosos de las teorías de la globalización (Baubock, 1994; Soysal, 1994; Sassen, 2001 y otros), esta tendencia responde a diversos factores, entre los que figuran la progresiva politización de la cuestión migratoria, sus efectos que trascienden las fronteras y el hecho de que el Estado también deba transformarse para dar respuesta a diversos desafíos migratorios tales como su desarrollo al interior 106 de bloques de integración regional. 
El artículo se enmarca en una investigación en curso que plantea como hipótesis general que, contemporáneamente, los factores externos que condicionan las políticas migratorias vienen adoptando cada vez mayor relevancia. Tomando como caso de estudio al argentino durante los años 2003-2007, se asume que los objetivos y la práctica de la política exterior se ven plasmados en el contenido de la política migratoria, y que la pertenencia a instancias de integración regional y los compromisos internacionales asumidos en la materia, influyen de forma significativa en la elaboración y orientación que asume la misma.

Dada la complejidad de la cuestión y por razones de economía argumentativa, en este artículo se analizará sólo una de las dimensiones expresadas: aquella que intenta interpretar el lugar que ocupa el Mercosur en la política migratoria nacional, y concretamente, revelar si se ha convertido en una instancia de influencia en su definición durante la etapa ya mencionada.

\section{Metodología}

La investigación parte de considerar a una política migratoria como una política pública que comprende al “(...) conjunto de normas, leyes, prácticas e instrumentos estatales destinados a regular el acceso secuencial de los extranjeros a diferentes esferas de la sociedad de acogida y, como prolongación natural, el acceso gradual a la titularidad de derechos" (López Sala, 2005, p. 112). Como toda política pública, está constituida por un conjunto de medidas concretas que conforman su verdadera sustancia; comprende una determinada forma de asignación de recursos; se inscribe en un marco general de acción -de ahí que se la pueda distinguir de simples medidas aisladas-; tiene la capacidad de afectar a un determinado público, y define, obligatoriamente, metas y objetivos definidos en función de normas o valores (Müller, 2006).

El trabajo se sustentó en un diseño de investigación de tipo analítico-descriptivo que buscó revelar el papel desempeñado por el proceso de integración Mercosur en la definición y orientación que asumió la política migratoria nacional durante el período bajo estudio, a través de su dimensión explícita -constituida por la formalización de sus objetivos y acciones a través del discurso oficial y la legislación pertinente (Mármora, 2002)-. De este modo, se presentan los resultados de un análisis realizado sobre tres planos centrales:

a) - El de la retórica estatal, a partir del examen del discurso de los principales referentes de la dirigencia gubernamental y del ámbito migratorio (Presidente de la Nación, Ministro del Interior, Director Nacional de Migraciones, diplomáticos y cancilleres). Aquí se seleccionaron documentos basados principalmente en intervenciones públicas, cuyo examen apuntó a descifrar si la integración regional fue utilizada por las autoridades argentinas como elemento de fundamentación del tipo de política migra- 
toria adoptado, su vinculación con los objetivos declarados, entre otros. Como marco conceptual para su análisis se adopta la perspectiva de Mármora (2002), quién asume que el diseño y justificación de las políticas migratorias se apoya generalmente en una serie de propuestas que conforman el «discurso argumental» de las mismas. En este plano, "Los principales fundamentos utilizados históricamente han estado vinculados con los derechos humanos del migrante y su familia, el desarrollo económico, la mano de obra, la estructura social, las relaciones internacionales, el espacio físico y el medio ambiente" (p. 109); variando el peso de cada uno de estos temas de acuerdo con cada momento histórico y a los proyectos nacionales e ideologías predominantes.

b)- En el de los marcos normativos que regulan la materia, a través de un análisis hermenéutico de la legislación elaborada durante el período examinado, etapa de activa renovación de los marcos regulatorios en el contexto de la instalación del «nuevo paradigma» (Nicolao, 2011). Esta dimensión incluyó el examen de la nueva ley de migraciones, decretos emitidos por el Poder Ejecutivo Nacional, disposiciones de la Dirección Nacional de Migraciones -en adelante DNM-, y compromisos asumidos en el marco del Mercosur. El análisis pretendió observar si las transformaciones de la legislación migratoria de estos años atañen en algún aspecto a la integración regional, de qué modo y con qué implicancias. Para ello, y siguiendo a Novick (1992), se parte de concebir al concepto de ley que como el elemento ideológico-concreto que elaboran los grupos -o el grupo- que en un momento histórico puntual detentan el poder político para explicar, comprender y legitimar un conflicto específico de intereses, intentando mediante ella -la ley- resolverlo a su favor.

c)- Fuera de la dimensión explícita de la política migratoria y para complementar las aproximaciones anteriores, una tercera dimensión de análisis se concentró en el comportamiento adoptado por el Estado argentino en los órganos del Mercosur dedicados al tratamiento de la problemática migratoria. Se examinó la performance de la delegación argentina en la Reunión de Ministros del Interior del Mercosur (en adelante RMI) y el Foro Especializado Migratorio del Mercosur (en adelante FEM), por constituir las dos instancias en las cuáles se aborda de forma sistemática la cuestión migratoria en dicho espacio regional, pretendiendo observar la forma de participación y el grado de compromiso asumido por los representantes argentinos en la gestión migratoria regional y las implicaciones de dicha participación. Para ello se acudió al análisis de las memorias institucionales de ambas instancias.

\section{Resultados}

\section{Argentina: la integración regional y la política migratoria (2003-2007)}

A partir del año 2003 y durante los cuatro años de presidencia de Kirchner en Argentina, se produce toda una serie de modificaciones en los marcos normativos y re- 
gulatorios nacionales en materia migratoria. Los atributos que presentan estas medidas dan cuenta de un rotundo cambio de orientación en la política migratoria de este país que, a grandes rasgos, asume un enfoque más aperturista, regionalista, y con una fuerte impronta en materia de derechos humanos. De forma resumida, estos instrumentos consagraron nuevos derechos a los inmigrantes que antes les eran negados; instalaron como eje prioritario la regularización migratoria de los extranjeros, compromiso dirigido a resolver la principal problemática migratoria de aquel momento: la existencia de bolsones de inmigrantes irregulares procedentes de la región -consecuencia de casi tres décadas de una legislación migratoria restrictiva y prácticas administrativas burocráticas y discriminatorias en la gestión de dichos trámites- y las consecuencias que ello acarreaba en términos de abusos y violación a los derechos humanos de esta población .

Esta transformación se vio acompañada de un punto de inflexión en el discurso político sobre las migraciones internacionales, y especialmente sobre las de origen regional, ya que desde el Estado nacional comenzó a presentarse una nueva visión del fenómeno migratorio, radicalmente opuesta a la que predominó en el decenio precedente. En el marco de estas transformaciones debe interpretarse el siguiente análisis que aborda el resultado de la investigación en los tres planos mencionados.

\section{El lugar de la integración regional en el discurso migratorio del Estado argentino}

Durante el decenio de 1990, la legislación migratoria restrictiva, las prácticas administrativas obstaculizadoras en los trámites de regularización, se conjugaron con el tinte discriminatorio del discurso oficial para dar lugar al contexto más desfavorable que vivió la población extranjera regional desde la recuperación de la democracia. En esta década, pero principalmente en su segundo quinquenio, se instaló un discurso oficial xenófobo y estigmatizante hacia los inmigrantes regionales, los cuáles fueron utilizados como chivos expiatorios por la clase dirigente argentina, en quienes depositaron la responsabilidad por distintas problemáticas sociales que padecía el país (principalmente, incremento del desempleo, de la inseguridad y saturación de los servicios sociales) (Oteiza \& Aruj, 1997).

A partir de 2003, se produjo un punto de inflexión en este aspecto y las migraciones internacionales, especialmente las de origen sudamericano, dejaron de convertirse en un fenómeno indeseado, en un «problema» para resolver, y se volvió a reconocer su aporte al país de destino, destacándose especialmente su contribución en el campo de la economía y la cultura (Domenech \& Magliano, 2008). Esta transformación se vinculó al proceso de modificación del patrón migratorio nacional, y concretamente, al hecho de que Argentina es por un lado Estado receptor, pero también emisor de migrantes internacionales a países desarrollados con políticas migratorias restrictivas.

La migración es un fenómeno natural y tan antiguo como la humanidad; sin embargo, en un escenario mundial de fuerte interdependencia, donde los capi- 
tales se mueven con libertad, paradójicamente se discute hoy más que nunca el derecho a migrar. Países que hasta hace pocos años eran generadores de grandes flujos de migrantes se han convertido en receptores de los mismos. Naciones que tradicionalmente recibieron inmigrantes hoy ven emigrar a sus nacionales. Estados que basaron su desarrollo en la mano de obra extranjera hoy la consideran indeseable. El hecho de que el hombre busque una mejor condición de vida, no debería ser reprochable y mucho menos penalizado (Palabras del Director Nacional de Migraciones, Dr. Ricardo E. Rodríguez, Encuentro Iberoamericano de Migración y Desarrollo, Madrid, 18 y 19 de julio de 2006)

En este marco, comenzó a asomar un discurso migratorio que intenta rescatar elementos de la tradicional política migratoria argentina de puertas abiertas, conjugado con la prioridad de regularizar la situación de la población extranjera regional. En lugar de poner el acento en la promoción y el fomento de la inmigración como en el período de las migraciones de ultramar, se privilegia ahora favorecer el desarrollo migratorio en un marco de legalidad e incrementar el reconocimiento de derechos a la población extranjera en pie de igualdad con los nacionales, dirigido a favorecer su integración a la sociedad receptora. Como señalan especialistas en la materia, se pasó de la retórica de la exclusión a la retórica de la inclusión en el ámbito migratorio (Domenech \& Magliano, 2008).

La legalidad constituye la base de toda sociedad democrática y es la única forma de que el extranjero logre su integración plena a la comunidad de recepción. Desde lo ético estamos convencidos que Argentina debe volver a su política migratoria amplia. Desde lo material entendemos que ello conllevará innumerables ventajas... (Palabras del Director Nacional de Migraciones, Dr. Ricardo E. Rodríguez, Encuentro Iberoamericano de Migración y Desarrollo, Madrid, 18 y 19 de julio de 2006).

(...) tiene que haber una política migratoria que tiene que velar por la incorporación clara y concreta del ser humano que viene a vivir a un país determinado, en este caso a la Argentina, que tenga las mismas posibilidades, las mismas venturas, las mismas visiones y rumbos que tenemos el resto de los argentinos...

Por eso, igualdad de responsabilidades, igualdad de derechos, igualdad de posibilidades y una Patria Grande que nos contenga en una etapa inicial a todos los que integramos el Mercosur y los países del América del Sur (Discurso del Presidente de la Nación, Dr. Néstor Kirchner en la presentación del Plan Nacional de Normalización Documentaria Migratoria, Buenos Aires, 14 de diciembre de 2005).

Vinculado a lo anterior, y como rasgo novedoso, la retórica migratoria estatal comenzó a vincularse a dos pilares esenciales a los cuáles se aludió de modo permanente como cimentando la nueva política migratoria: por un lado, el respeto y protección de los derechos humanos de la población extranjera, emergiendo como la dimensión ética que 
atraviesa integralmente a la política migratoria, y por otro, la necesidad de adecuar ésta al contexto regional, y en este sentido, a que la gestión de las migraciones acompañe la profundización del proyecto de integración Mercosur. En otras palabras, derechos humanos e integración regional se convirtieron en dos elementos infaltables en el discurso migratorio del Estado argentino, y desde la conceptualización de Mármora (2002), en los fundamentos del «discurso argumental» en el que se apoyó el nuevo paradigma:

Creemos fervientemente que la nueva lógica de las políticas migratorias debe fundamentar su concepción como parte de las relaciones internacionales entre los países, buscar su inserción en los objetivos de integración, y por sobre todo responder a la dimensión ética del respeto por los derechos humanos (Palabras del Director Nacional de Migraciones, Dr. Ricardo E. Rodríguez, Encuentro Iberoamericano de Migración y Desarrollo, Madrid, 18 y 19 de julio de 2006).

Así, la Argentina conjuga su acervo constitucional con su convicción democrática, fortaleciendo dos de sus objetivos más preciados: respeto por los derechos humanos y fortalecimiento de la integración regional. (Palabras del Presidente de la Nación, Dr. Néstor Kirchner, XVI Cumbre Iberoamericana, República Oriental del Uruguay, 4 y 5 de noviembre de 2006).

La incorporación de la perspectiva regionalista demuestra el vínculo cada vez más estrecho que existe entre una política migratoria y los objetivos de política exterior de un determinado país. La inserción internacional de Argentina que en la etapa estudiada -y en la actual- encuentra en los vínculos con los países sudamericanos su marco privilegiado (Colombo, 2004) contempla entre sus metas más relevantes la profundización del bloque regional en sus dimensiones políticas y sociales, entre las cuáles la movilidad de los ciudadanos al interior del mismo, constituye un factor elemental. Pero fundamentalmente, da cuenta de una opción de política migratoria que apunta a potenciar las instancias multilaterales de diálogo y cooperación, apostando a «una gobernabilidad compartida de las migraciones internacionales» y a «lograr una postura regional sobre el fenómeno migratorio». Así como también, forma parte de la adecuación de la política migratoria a la realidad contemporánea de las migraciones en el país, determinada por el predominio de inmigrantes originarios de los países miembros y asociados del bloque Mercosur:

Los objetivos de la política que impulsa la República Argentina en esta materia se han ido modificando en los últimos años, buscando orientar la gobernabilidad de las migraciones a través de la suscripción de convenios bilaterales y de acuerdos regionales basados en la reciprocidad de trato y de derechos de sus nacionales y en la facilitación para la concesión de la residencia, teniendo como premisa encarar soluciones conjuntas y consensuadas entre los países (Sitio oficial del Ministerio del Interior de la Nación, Dirección Nacional de Migraciones. Asuntos Internacionales. Recuperado de 12 de diciembre de 2005, de http:// www.migraciones.gov.ar). 
La participación de mi país se enmarca en un contexto de integración regional... y en la decisión de promover el tratamiento multilateral de las migraciones superando así la visión basada exclusivamente en el Estado y su soberanía.

(...) los países debemos abordar el tema buscando mecanismos de cooperación, integración y asumiendo la responsabilidad compartida, no ya como expresión de deseo sino como hechos concretos (Intervención del Viceministro de Política Latinoamericana del Ministerio de Relaciones Exteriores, Comercio Internacional y Culto, Leonardo Franco, en el marco del Dialogo de Alto Nivel sobre Migración Internacional y Desarrollo, Nueva York, 15 de septiembre de 2006).

De esta manera, el análisis del discurso oficial migratorio permite afirmar que, a partir del año 2003, el proceso de integración regional comenzó a jugar un rol inédito en la definición de la política migratoria. Al menos en el plano explícito, se la presentó como sustentada y enmarcada en los esfuerzos de profundización de la integración mercosureña, y se intentó transmitir una imagen de Argentina abierta al mundo, pero especialmente a América del Sur, -lo cuál adquiere sentido a partir de su condición de principal receptor migratorio de dicho espacio geográfico-. Del mismo modo, como una manera de tomar distancia de las opciones políticas restrictivas y unilaterales que priman a escala global, la integración regional, y concretamente el Mercosur, apareció como el ámbito adecuado para plasmar opciones multilaterales y de cooperación en el tratamiento político que recibe el tema.

\section{El lugar de la integración regional en la normativa migratoria argentina}

En el plano de la normativa migratoria, el estudio arrojó distintos elementos de relevancia. Entre los más destacables figuran los derivados de la nueva ley de migraciones (Ley núm. 25.871/2003), que se constituyó en la primera normativa migratoria en la historia argentina que cita un proceso de integración regional, disponiendo el derecho del Estado argentino a establecer un trato diferenciado a los inmigrantes originarios de los Estados con los cuáles está asociado; y es también la primera vez que una normativa migratoria nacional incorpora disposiciones que atañen a metas de integración regional, y en concreto, a su fortalecimiento y profundización a través del objetivo de la libre circulación de personas.

(...) El principio de igualdad de trato no se considerará afectado por la posibilidad que tiene el Estado, conforme a los procedimientos establecidos en la Constitución y las leyes, de firmar acuerdos bilaterales de alcance general y parcial, que permitan atender fenómenos específicos, como el de la migración laboral fronteriza, ni por la posibilidad de establecer esquemas diferenciados de tratamiento entre los países que con la Argentina forman parte de una región respecto de aquellos países que resulten terceros dentro del proceso de regionalización, priorizando las medidas necesarias para el logro del objetivo final de la libre circulación de personas en el Mercosur (Ley 25.871, Artículo 18). 
El trato diferenciado a los inmigrantes procedentes de lo países del bloque se instaló definitivamente a partir del artículo núm. 23 , inciso "l" de la misma ley que introduce el criterio de nacionalidad, que garantiza a los extranjeros originarios de los Estados parte y asociados del Mercosur, que carezcan de antecedentes penales, el derecho a radicarse en la Argentina, pudiendo obtener a tal efecto una residencia temporaria, la cuál luego de transcurrido los plazos correspondientes y cumpliendo los requisitos establecidos, puede convertirse en permanente.

Este criterio de radicación, basado en la nacionalidad del peticionante, deviene del Acuerdo de Residencia para Nacionales de los Estados Partes del Mercosur, Bolivia y Chile firmado en el año 2002 , a partir del cual, cada uno de los países suscriptores se comprometía a aplicar esta misma regla para la tramitación de la residencia legal de los nacionales de cualquiera de los países firmantes que ingresaran o residieran en sus territorios; acuerdo que representó un paso trascendental en el tratamiento de la movilidad de las personas al interior del Mercosur. Pero como la entrada en vigencia de este convenio dependía de la efectiva internalización del mismo a las legislaciones nacionales de los países firmantes (proceso que demoró siete años ), así como la tardía reglamentación de la ley 25.871 impidió hasta 2010 hacer efectivo el artículo núm. 23, inciso 1, el gobierno argentino decidió acudir -mediante decreto del Poder Ejecutivo Nacional núm. 836/2004 y núm. 578/2005- a la creación e implementación de un Programa Nacional de Normalización Documentaria Migratoria para ciudadanos de los Estados Parte y Asociados del Mercosur, de manera de operacionalizar finalmente dicho criterio.

Esto significa que sin exigir reciprocidad al resto de los países miembros y asociados del Mercosur, Argentina decidió garantizar ese derecho de radicación de manera unilateral, y así ofrecer solución a la irregularidad de la población extranjera regional. En esta misma línea debe entenderse la Disposición 2079/2004 de la DNM, dirigida a suspender las medidas de expulsión aplicadas por el Estado hacia los nacionales de países limítrofes, con excepción de aquellas que estuvieren fundadas en la existencia de antecedentes penales.

También se ha observado que en el transcurso del período bajo estudio, el gobierno nacional se comprometió a ratificar diversas normas aprobadas por los organismos de decisión del Mercosur, cuya entrada en vigor se demoró precisamente por la falta de ratificación de los países miembros. Entre estas puede citarse el ya mencionado Acuerdo de residencia para los nacionales de los países del Mercosur (mediante ley núm. 25.903), y el similar que lo extiende a Bolivia y Chile (ley núm. 25.902); el Protocolo de Integración Educativa y Reconocimiento de Certificados, Títulos y Estudios de Nivel Primario y Medio No Técnico entre los Estados partes del Mercosur, Bolivia y Chile (ley núm. 25.905), entre otros.

Pero más relevante aún resultaron los nuevos convenios que fueron aprobados en la órbita del bloque mercosureño en el transcurso de estos años -muchos de los cuáles, 113 
como se observará en siguiente apartado, fueron resultado de iniciativas argentinas-. En lo que refiere a la movilidad al interior del bloque, vale citar el Acuerdo para la concesión de un plazo de 90 días a los turistas nacionales de los Estados Parte del Mercosur y Estados Asociados (Decisión del Consejo del Mercado Común 10/06); Acuerdo para la creación de la visa Mercosur (Decisión CMC 16/03); Acuerdo para la facilitación de actividades empresariales en el Mercosur (Decisión CMC 32/04); en el plano de los derechos de educación, Acuerdo de admisión de títulos, certificados y diplomas para el ejercicio de la docencia en la enseñanza del español y portugués como lenguas extranjeras en los Estados Parte (Decisión CMC 09/05); Acuerdo sobre gratuidad de visados para estudiantes y docentes de los Estados Parte del Mercosur (Decisión CMC 21/06). En materia de tráfico y trata de personas, Acuerdo contra el tráfico de migrantes entre los Estados Parte del Mercosur y el instrumento que lo hace extensivo a Bolivia y Chile (Decisión CMC 37/04); Programa para la erradicación del trabajo infantil (Resolución 36/06 del Grupo Mercado Común), entre otros.

En suma, más allá de esta cantidad de convenios suscritos en el ámbito regional, el elemento trascendental que emerge del plano normativo es la disposición que otorga derecho al Estado a establecer esquemas de tratamiento diferenciados hacia los inmigrantes procedentes de lo países del bloque que, aunque en este caso se consagra a través de una discriminación positiva hacia los extranjeros regionales en el acceso a la residencia, significa una puerta abierta para su futura profundización y extensión. De ahí la interpretación del enfoque regionalista que asume la nueva política migratoria.

\section{El liderazgo argentino en el ámbito migratorio del Mercosur}

De las memorias institucionales de la gestión 2003-2007 de la DNM se desprenden las metas explícitas de la política migratoria nacional, entre las cuales vale destacar uno de los objetivos centrales que ha guiado el trabajo de este organismo durante dicho período: posicionar a la Argentina como el líder regional en materia de políticas migratorias. Para cumplir esta meta, la Oficina de Temas Internacionales de la DNM realizó una activa labor durante estos años, concentrando sus actividades en la presentación de las ideas fuerza que inspiran la política migratoria argentina tanto en el Mercosur como en otros ámbitos regionales e internacionales. En esta línea se interpretó el desempeño de las autoridades argentinas en las instancias del Mercosur dedicadas al tratamiento de la cuestión migratoria.

El abordaje del tema migratorio dentro de los órganos del Mercosur ha resultado tradicionalmente marginal, dado que lejos de contar desde un inicio con un grupo de trabajo dedicado específicamente a esta materia, se debatió tradicionalmente en espacios relacionados a otras cuestiones (laborales, de fronteras, de previsión social). No obstante, en el año 2004 comenzaron las actividades del Foro Especializado Migratorio- dependiente de la RMI, el primer espacio en la historia del Mercosur concentrado

114 exclusivamente en el tratamiento de esta problemática. Uno de los primeros documen- 
tos que lanzó el FEM fue la Declaración de Santiago de Principios Migratorios, en el cuál se plasma el espíritu con el que los gobiernos encaran la política migratoria. El proyecto para esta declaración fue elaborado y presentado por la delegación argentina y aprobado por el resto de los gobiernos. A grandes rasgos, hace hincapié en reafirmar ante el resto del mundo la vocación de trabajar hacia una política migratoria apoyada en la dimensión ética de los derechos humanos y en la inserción de las relaciones internacionales de los países; apostar a mecanismos de diálogo multilateral abierto; adecuar la política migratoria a la realidad regional e internacional; priorizar las medidas de regularización migratoria como condición indispensable para la inserción de los inmigrantes a la sociedad de recepción; reconocer la importancia de la reunificación familiar; requerir a los países extra-bloque la reciprocidad en el trato a los inmigrantes en sus territorios; comprometerse a trabajar en el combate al tráfico ilícito de migrantes, trata de personas, y otras formas de delitos transnacionales; entre otros. Como puede observarse, los mismos reflejan los lineamientos centrales de la política migratoria argentina explicitados en las normas y en el discurso migratorio de dicho país.

De las memorias institucionales de la RMI y el FEM también se desprende un claro protagonismo de la delegación argentina en la presentación de iniciativas, proyectos y una activa participación de sus representantes en el diseño de la agenda de dichas instancias. Específicamente, destacan la elaboración de una enorme cantidad de proyectos destinados al logro de un mejor funcionamiento de los órganos que tratan las cuestiones migratorias en el Mercosur (iniciativa argentina para la creación de una reunión de Directores de Migraciones dentro del FEM y de elaboración de reglamento para el funcionamiento de dicha instancia; iniciativa argentina para la inclusión de los Ministros del Interior en las reuniones de los órganos decisorios del Mercosur; Proyecto de Modificación del reglamento interno de la RMI, entre otros).

También sobresalen las iniciativas argentinas dirigidas a instalar un seguimiento de los acuerdos firmados por el Mercosur, Bolivia y Chile, a partir de la presentación de un cuadro del estado de situación de los procesos de incorporación de dichos acuerdos a la normativa nacional de cada Estado. De hecho, la delegación argentina presentó durante estos años un estado de situación permanentemente actualizado en los distintos encuentros del FEM y propuso el intercambio de las normas migratorias de cada Estado parte de cara a logro de armonizaciones efectivas.

Asimismo, entre los proyectos más relevantes que las autoridades de este país han presentado en el FEM durante la etapa analizada figuran el Proyecto de Acuerdo sobre Tráfico Ilícito de Migrantes; el Proyecto sobre reglamentación de la documentación exigida para viajes de menores; una propuesta dirigida a la readmisión de nacionales de los Estados miembros residiendo en el exterior; el Proyecto sobre Plan de Acción del Mercosur para la lucha contra la trata de personas, entre otros. Finalmente, también destacan los esfuerzos de los representantes argentinos en la elaboración de propuestas de agenda para la CSM y para distintos foros migratorios de carácter internacional, 
intentando establecer una postura regional ante el tratamiento de las migraciones (caso del Foro Mundial de Migraciones y Desarrollo).

De este modo, sus aspiraciones a convertirse en el referente regional en materia de políticas migratorias -fortalecida por su condición de principal receptor migratorio del Mercosur-, condujo al país a adoptar un gran protagonismo y activismo en las instancias mencionadas de manera de instalar sus visiones y principios entre el resto de los países del bloque.

\section{Conclusiones}

Este trabajo permite demostrar que el Mercosur jugó un papel sustancial en la política migratoria argentina durante el período bajo estudio, aspecto que se puso de manifiesto en los tres planos examinados. De la dimensión explícita de la política migratoria se deduce su presentación como elemento que contribuye a la profundización y fortalecimiento de la integración regional, y a ésta, como la plataforma escogida por Argentina para el desarrollo de estrategias de cooperación, diálogo y construcción de consensos, siguiendo una tendencia contrapuesta a la que predomina en el contexto global contemporáneo.

En el terreno de la elaboración de normativa, se produjo un avance sustancial a través del reconocimiento del derecho del Estado nacional a establecer un tratamiento diferenciado hacia los inmigrantes procedentes del bloque. Si bien este derecho se utilizó en el plano concreto de la radicación legal, por el grave problema coyuntural de la irregularidad de los inmigrantes regionales, se trata de una disposición que abre varias puertas a esquemas de tratamiento diferenciados en materia de reconocimiento de distintos derechos, en beneficio del grupo inmigratorio mayoritario. En tercer lugar, se observó un importante activismo de la Argentina en los órganos migratorios del Mercosur, a través de la proposición de iniciativas, proyectos, elaboración de agenda, en correspondencia con la aspiración de este país a convertirse en el referente o líder regional en materia de políticas migratorias. Incluso se ha podido observar un notable esfuerzo argentino por trasladar los principios que rigen la política migratoria nacional hacia el ámbito mercosureño.

En suma, la dimensión internacional de la política migratoria argentina se ha fortalecido considerablemente, y con ella, el papel desempeñado por el proceso de integración regional en su definición, pero de una manera particular: como consecuencia de la decisión política nacional de imprimir una perspectiva regionalista a su política migratoria. Tanto la decisión de fortalecer su participación en instancias migratorias regionales, su pretensión de definir determinados cursos de acción a través de procesos de consulta y cooperación regionales, su aspiración de instalar sus objetivos migratorios en el ámbito mercosureño, su preocupación coyuntural de dar respuesta al problema de la irregularidad de un modo regionalista, fueron todos resultados de una decisión política nacional. 
Podría decirse entonces que en lugar de asistir a un proceso desnacionalizador de las políticas migratorias por parte del bloque regional, hemos asistido a la decisión nacional de regionalizar la política migratoria. Así, en contraposición a la visión de los teóricos de la globalización, que vinculan la regionalización o internacionalización de las mismas como señal del debilitamiento de la soberanía de los Estados en cuanto a su capacidad para regular las migraciones, en este caso la regionalización ha sido consecuencia directa de una determinación nacional y soberana. Cabría reflexionar de aquí en adelante sobre la forma en que estas instancias de integración se convierten en espacios de interés para países que, como Argentina, deciden focalizar, consensuar y definir su política migratoria en ámbitos compartidos con los Estados de origen de su población inmigrante. 


\section{Bibliografía}

Albarracín, J. (2005). "Inmigración y la Argentina moderna: ¿un matrimonio en la salud y en la enfermedad con los europeos?”. En E. Domenech (Comp.), Migraciones contemporáneas y diversidad cultural en Argentina (19-40). Córdoba: CEA - UNC.

Arango, J. (2000). “Enfoques conceptuales y teóricos para explicar la migración”. Revista Internacional de Ciencias Sociales, 165, (33-47).

Baubock, R. (1994). Transnational Citizenship: Membership Rights in International Migration. London: Edward Elgar.

Brubaker, W.R. (1992). Citizenship and Nationhood in France and Germany. Cambridge: Cambridge University Press.

Brubaker, W.R. (1990). "Immigration, Citizenship and The Nation State in France an Germany: A Comparative Historical Analysis". International Sociolgy, (4) 5, (379-407).

Brubaker, W.R. (1989). "Citizenship and Naturalization: Policies and Politics". En W.R. Brubaker (Ed.), Immigration and the Politic of Citizenship in Europe and North America (99-127). Nueva York: Lanham.

Cerrutti, M (2009). “Diagnósticos de las poblaciones de inmigrantes en la Argentina”. En Serie de Documentos de la Dirección Nacional de Población. 02. Buenos Aires: Dirección Nacional de Población - OIM.

Colombo, S. (2005). "La estrategia de integración argentina (1989-2004): cambios y continuidades a partir de la crisis del orden neoliberal". Revista Historia Actual HAOL, 8, (133-149).

Cornelius, W. A., Martin, \& Hollifield, J. (1994). Controlling Immigration: A Global Perspective. Stanford CA: Stanford University Press.

Devoto, F. (2003). Historia de la inmigración en Argentina (3ºd.). Buenos Aires: Editorial Sudamericana.

Domenech, E. (2007). "La agenda política sobre migraciones en América del Sur: el caso de la Argentina". Revue europeenne des migrations internacionales, (1) 23, (71-94).

Doménech, E. \& Magliano, M. J. (2008). “Migración e Inmigrantes en la Argentina reciente: políticas y discursos de exclusión e inclusión”. En M. del C. Zabala Argülles (Comp.). Pobreza, exclusión social y discriminación étnico-racial en América Latina y El Caribe (423-448). Bogotá: Siglo del Hombre Editores / CLACSO.

Dublanc, M. L. (2009). “El debate sobre derechos humanos y políticas migratorias en los foros latinoamericanos". En P. Ceriani Cernadas y R. Fava (Eds.). Politicas migratorias y derechos bumanos (pp. 245-261). Remedios de Escalada: De la UNLA - Universidad Nacional de Lanús.

Entzinger, H. (2000). “The Dynamics of Integration Policies: a multidimentional model”. En R. Koopmns y P. Statham (Comps.). Challenging Immigration and Ethnic Relations Politics. Comparative European Perspectives (97-118). Oxford: Oxford University Press.

Faist, T. (1996). "Inmigration, integration and the Welfare State: Germany and USA in a comparative perspective”. En R. Bauböck, A. Heller y A. Zolberg (Comps.). The Challenge of 
Diversity: Integration and Pluralism in Societies of Inmigration (pp. 227-259). Avebury: Aldershot.

Hammar, T. (1992). Laws and policies regulating population movements: A European perspective. En M. Kritz; L. Lean Lim y H. Zlotnik (Comps.). International Migration Systems: An Approach (pp. 245-262). Oxford: Clarendon Press.

Hammar, T. (1990). Democracy and the Nation State: Aliens, Denizens and Citizens in a World of International Migration. Avebury: Aldershot.

Heckmann, F. \& Schnapper, D. (Comps.). (2003). The integration of Immigrants in European Societies. National Differences and Trends of Convergence. Sttutgart: Lucius \& Lucius.

Hollifield, J. (2000). The Politics of International Migration: How can we bring the State back in. En C. Brettell y J. Hollifield (Comps.). Migration Theory. Talking across disciplines (pp. 137-185). Londres: Routledge.

Hollifield, J. (1992). Immigrants, Markets and States. Cambridge, MA: Harvard University Press.

Instituto Nacional de Estadística y Censos (INDEC) de la República Argentina. Censo Nacional de Población, Hogares y Vivienda, 2001.

Joppke, C. (1999). How Migration is Changing Citizenship: a comparative Overview. Ethnic and Racial Studies, (4) 22, 629-653.

Loescher, G. \& Scanlan, J. A. (1986). Calculated Kindness: Refugees and America's Half-Open Door, 1945 to the Present. New York: The Free Press.

López Sala, A. M. (2005). Inmigrantes y Estados: la respuesta política ante la cuestión migratoria. Barcelona: Anthropos.

Mármora, L. (2004). Las leyes de migración como contexto normativo. En R. Giustiniani, (Comp.). Migración: un derecho humano (pp. 59-65). Buenos Aires: Prometeo.

Mármora, L. (2003). Políticas migratorias consensuadas en América Latina. Estudios Migratorios Latinoamericanos, (50) 17, 111-142.

Mármora, L. (2002). Las políticas de migraciones internacionales ( $2^{\circ}$ ed.). Buenos Aires: OIM - Paidós.

Massey, D. (1999). International Migration at the down of the Twenty-First Century: The role of the State. Population and Development Review, (2) 25, 303-322.

Meyers, E. (2000). Theories of International Immigration Policy: A comparative analysis. International Migration Review, 3, 1245-1282.

Miller, M. J. (1992). Evolution of Policy Modes for Regulating International Labor Migration. En M. M. Kritz, L. L. Lim and H. Zlotnik (Eds.) International Migration Systems (pp. 300-314).Oxford: Clarendon Press.

Miller M. J. \& Papademetriou, D. G. (1983). Immigration and U.S. Foreign Policy. En M. J. Miller and D. G. Papademetriou (Eds.). The Unavoidable Issue: US. Immigration Policy in the 1980s. Philadelphia: Institute for the Study of Human Issues.

Mitchell, C. (1992). Western Hemisphere Immigration and United States Policy. University Park, PA: The Pennsylvania State University Press. 
Muller, P. (2006). Las políticas públicas. Buenos Aires: Universidad Externado de Colombia.

Nicolao, J. (2011). Política migratoria argentina: «el nuevo paradigma». Los derechos humanos, el enfoque regional y la tradición aperturista. En S. Colombo (Comp.). La inserción internacional de Argentina durante la presidencia de Néstor Kirchner. Un cambio de época (109-140). Tandil: El autor.

Novick, S. (2008). "Migración y Políticas en Argentina. Tres Leyes para un país extenso (18762004)". En S. Novick (Comp.). Las migraciones en América Latina (131-152). Buenos Aires: Catálogos.

Novick, S. (1997). "Políticas migratorias en la Argentina". En E. Oteiza; S. Novick y R. Aruj (Comps.). Inmigración y discriminación. Políticas y discursos (83-139). Buenos Aires: Grupo Editor Universitario.

Novick, S. (1992). Politica y población. Argentina 1870-1989. Buenos Aires: Centro Editor de América Latina.

Novick, S. (1991). "Ley y población: la experiencia Argentina”. En S. Torrado (Comp.). Política y Población en la Argentina. Claves para el debate (119-174). Buenos Aires: Ediciones de La Flor.

Oteiza E. \& Aruj, R. (1997). "Inmigración real, inmigración imaginaria y discriminación en Argentina". En E. Oteiza; S. Novick y R. Aruj (Comps.). Inmigración y discriminación. Políticas $y$ discursos (11-56). Buenos Aires: Grupo Editor Universitario.

Salomon, K. (1991). Refugees in the Cold War: Towards a New International Refugee Regime. Lund: Lund University Press.

Sassen, S. (2001). ¿Perdiendo el control? La soberanía en la era de la globalización. Barcelona: Editorial Bellaterra.

Skran, C. M. (1995). Refugees in Inter-War Europe: The Emergence of a Regime. Oxford: Clarendon Press.

Soysal, Y. (2000). "Citizenship and Identity: Living in Diasporas in Post-War Europe?". Ethnic and Racial Studies, (1) 23, (10-25).

Soysal, Y. (1994). The Limits of Citizenship. Chicago: The University of Chicago Press.

Teitelbaun, M. S. (1984). "Immigration, Refugees, and Foreign Policy”. International Organization, 38(3), 429-450.

Weiner, M. (1993). International Migration and Security. Boulder Co: Westview Press.

Zolberg, A. (1992). "Labor Migration and International Economic Regimes: Bretton Woods and After". In M. M. Kritz, L. L. Lim and H. Zlotnik (Eds.). International Migration Systems (315-334). Oxford: Clarendon Press.

Zolberg, A. (1989). “The Next Waves: Migration Theory for a Changing World”. International Migration Review, (3) 23, (403-430).

\section{Fuentes:}

Decreto del Poder Ejecutivo Nacional Núm. 836/2004

Decreto del Poder Ejecutivo Nacional Núm. 578/2005

Discurso del Presidente de la Nación, Dr. Néstor Kirchner, en la presentación del Plan Nacional de Normalización Documentaria Migratoria, Buenos Aires, 14 de diciembre de 2005. 
Disposición de la Dirección Nacional de Migraciones núm. № 20.880/2005

Disposición de la Dirección Nacional de Migraciones núm. № 2079/2004

Intervención del Embajador Leonardo Franco, Viceministro de Política Latinoamericana del Ministerio de Relaciones Exteriores, Comercio Internacional y Culto en el marco del Dialogo de Alto Nivel sobre Migración Internacional y Desarrollo, Nueva York, 15 de septiembre de 2006.

Ley Nacional No 25.871/2003: Ley de Migraciones.

Mercosur/RMI/CT/ACTA Núm. 04/02.

Palabras del Director Nacional de Migraciones, Dr. Ricardo E. Rodríguez, Encuentro Iberoamericano de Migración y Desarrollo, Madrid, 18 y 19 de julio de 2006.

Palabras del Presidente de la Nación, Dr. Néstor Kirchner, en la XVI Cumbre Iberoamericana, República Oriental del Uruguay, 4 y 5 de noviembre de 2006. 
